\title{
Tranilast strongly sensitizes pancreatic cancer cells to gemcitabine via decreasing protein expression of ribonucleotide reductase 1
}

\author{
MAYUMI MITSUNO, YOSHIHIKO KITAJIMA, KAZUMA OHTAKA, KEITA KAI, KAZUYOSHI HASHIGUCHI, \\ JUN NAKAMURA, MASATSUGU HIRAKI, HIROKAZU NOSHIRO and KOHJI MIYAZAKI
}

Department of Surgery, Saga University Faculty of Medicine, Nabeshima 5-1-1, Saga 849-8501, Japan

Received September 28, 2009; Accepted November 6, 2009

DOI: 10.3892/ijo_00000505

\begin{abstract}
Gemcitabine (Gem) is a dFdC analogue with activity against several solid tumors. Gem is intracellularly phosphorylated by $\mathrm{dCK}$, leading to the production of the metabolite dFdCDP. dFdCDP exhibits the cytotoxic effect by inactivating ribonucleotide reductase larger subunit 1 (RRM1), which is a rate limiting enzyme for de novo DNA synthesis. To date, RRM1 expression is believed to determine sensitivity to Gem in pancreatic and non-small cell lung cancer. In the present study, we found that an anti-allergic drug, tranilast strongly enhanced the sensitivity of pancreatic cancer cell line KP4 to Gem. In growth inhibition assay, $100 \mu \mathrm{M}$ of tranilast plus $1 \mu \mathrm{M}$ of Gem more strongly suppressed the growth of KP4 at 12.7-fold in $\mathrm{IC}_{50}$ than single Gem treatment, while this compound no longer affected the sensitivity to other drugs such as 5-fluorouracil, irinotecan or paclitaxel. FACS and TUNEL analysis demonstrated the increased apoptotic population in KP4 cells under tranilast plus Gem, compared with single Gem treatment. In Western blot analysis, tranilast treatment decreased RRM1 expression at protein level with dose-dependency in KP4 cells. Proteasome inhibitor MG132 disturbed the reduction of RRM1 expression in tranilast treated KP4 cells, indicating protein degradation by the activated proteasome. Transfection using siRNA against RRM1 increased the sensitivity of KP4 to Gem, suggesting that RRM1 suppression is an important step in increasing Gem efficacy. Finally, we demonstrated that tranilast reduced RRM1 protein and increased Gem efficacy in 4 other pancreatic cell lines. In a future, a novel chemotherapeutic strategy
\end{abstract}

Correspondence to: Dr Yoshihiko Kitajima, Department of Surgery, Saga University Faculty of Medicine, Nabeshima 5-1-1, Saga 849-8501, Japan

E-mail: kitajiy@cc.saga-u.ac.jp

Abbreviations: dFdC, 2',2'-difluorodeoxycytidine; Gem, gemcitabine; dCK, deoxycytidine kinase; dFdCDP, 5'-diphosphate nucleotide; dFdCTP, 5'-triphosphate nucleotide; RRM1, ribonucleotide reductase larger subunit 1

Key words: trainlast, gemcitabine, pancreatic cancer, ribonucleotide reductase larger subunit 1 , chemo-sensitivity by Gem along with tranilast might improve Gem efficacy against pancreatic cancer.

\section{Introduction}

Pancreatic adenocarcinoma is one of the most lethal diseases and a frequent cause of cancer related death $(1,2)$. Most patients with pancreas cancer have a poor outcome due to difficulty in its early diagnosis, its highly invasive with metastatic features. In patients with pancreatic cancer, the overall survival is less than 6 month after diagnosis (3) and a disease recurrence is up to $80 \%$ of the resected tumors within 2 years (4). The 5-year survival rate of patients who underwent surgical resection remains at only $15-20 \%(5,6)$.

Effective chemotherapy is thus important in order to prolong the survival of pancreatic cancer patients, especially in non-resectable or non-curative resection cases. To date, gemcitabine (Gem), (2',2'-difluorodeoxycytidine:dFdC) has been accepted as the standard treatment for advanced pancreatic cancer, since a randomized study by Burris et al in 1997 demonstrated that Gem treatment had a survival benefit, compared with fluorouracil (7). However, the median survival of patients with advanced pancreatic cancer treated by Gem is still about 6 months (7-9), indicating the pressing need for development of effective chemotherapy. Gem exhibits cell phase specificity, primarily killing cells undergoing DNA synthesis. Gem is metabolized intracellularly by deoxycytidine kinase to 5'-diphosphate (dFdCDP) and 5'-triphosphate (dFdCTP) nucleotides. The cytotoxic effect is attributed to a combination of two actions performed by those two metabolites. First, dFdCDP inhibits ribonucleotide reductase larger subunit (RRM1), which is responsible for catalyzing the reaction that generates the deoxyribonucleotides required for DNA synthesis and repair; inhibition of ribonucleotide reductase (RNR) causes a reduction in the cellular concentration of the four DNA monomers. Second, dFdCTP competes with the natural deoxycytidine 5'-triphosphate (dCTP) for incorporation into the replicating DNA; once one molecule of $\mathrm{dFdCTP}$ is incorporated, an additional deoxyribonucleotide is added to the growing DNA strands, thereafter, DNA synthesis can no longer proceed $(9,10)$. Especially, several in vitro and in vivo studies demonstrated the involvement of RRM1 overexpression in $\mathrm{dFdC}$ resistance of pancreatic as well as nonsmall cell lung cancer, indicating that RRM1 expression is a major predictor for Gem treatment (11-16). If some agent 
decreases RRM1 expression, it is promising that the pancreatic cancer responds more strongly to Gem.

Tranilast, N-(3',4'-dimethoxycinnamoyl) anthranilic acid, has been used clinically for more than 20 years in Japan (17). This drug is taken orally and exerts the drug effect against allergic diseases such as bronchial asthma, allergic rhinitis, atopic dermatitis and allergic conjunctivitis $(17,18)$. It has been reported that this compound is also effective in disease with excessive fibrosis such as keloid, because it inhibits fibroblast proliferation leading to the suppression of collagen accumulation (19-25). Recently, several reports showed that tranilast inhibits the proliferation of several cancer cell lines (26-29). However, no study has addressed the effect of tranilast on sensitivity to anticancer drugs in pancreatic cancer.

In the present study, we first evaluated whether or not tranilast alters the sensitivity of a pancreatic cancer cell line KP4 to the anticancer agents Gem, 5-fluorouracil (5-FU), cisplatin (CDDP), irinotecan (CPT-11) and micro-tubule inhibitor, paclitaxel (PTX). The result revealed a novel finding that tranilast strongly increased Gem efficacy in this cell line. We thus attempted to clarify the mechanism of the sensitizing effect of tranilast on Gem efficacy. We herein present an in vitro model of a novel strategy using tranilast plus Gem for the treatment of pancreatic cancer.

\section{Materials and methods}

Cell line and culture. KP4, PK-8, PK-9, PK-1 and PK-59 are human pancreas cancer cell lines. KP4 and PK-59 were purchased from the RIKEN Cell Bank (Ibaragi, Japan). PK-8, PK-9 and PK-1 were purchased from the institute of development, Aging and Cancer, Tohoku University (Sendai, Japan). All cell lines were cultured in RPMI-1640 medium (Sigma, St. Louis, MO, USA) supplemented with $10 \%$ heat-inactivated fetal bovine serum (FBS) (JRH Bioscience, Lenexa, KS, USA) and $100 \mu \mathrm{g} / \mathrm{ml}$ kanamycin (Meiji, Tokyo, Japan). These cell lines were grown at $37^{\circ} \mathrm{C}$ in a humidified atmosphere containing $20 \% \mathrm{O}_{2}$ and $5 \% \mathrm{CO}_{2}$ in air.

Reagents. Tranilast, N-(3,4-dimethoxycinnamoyl)-anthranilic acid (MW 327.24) was a generous gift of Kissei Pharmaceutical Co., Ltd. (Nagano, Japan). Powder of tranilast was dissolved in $\mathrm{N}$-, N-dimethylformamide and diluted with medium to final concentration before use. Gem was kindly supplied by Eli Lilly Pharmaceuticals (IN, USA). 5Fluorouracil (5-FU) was purchased from Kyowa Hakko Pharmaceutical Co., Ltd. (Tokyo, Japan), cisplatin (CDDP) from Nippon Kayaku Co., Ltd. (Tokyo, Japan) and paclitaxel (PTX) from Bristol-Myers K.K. (NY, USA). Irinotecan (CPT-11) was supplied from Yakult Co., Ltd. (Tokyo, Japan) and $10 \mathrm{mM}$ of stock solution was prepared in DMSO and diluted in medium at the approximate dose immediately before use. MG132, a specific proteasome inhibitor, was purchased from Sigma and prepared as a 1-mM stock in DMSO, and stored at $-20^{\circ} \mathrm{C}$ until use.

Analysis of drug sensitivity. Sensitivity to various drugs was analyzed by the MTT [3(4,5-dimethylthiazol-2-yl)-2,5diphenyltetrazolium bromide] assay using a Cell Titer96
Non-Radioactive Cell Proliferation Assay kit (Promega, Madison, WI, USA).

KP4 was seeded in 96-well culture plates each $1 \times 10^{4}$ cell/ well and incubated at $37^{\circ} \mathrm{C}$ in a humidified atmosphere overnight. Then the cells were exposed to tranilast for $48 \mathrm{~h}$, at a concentration ranging from 0 to $400 \mu \mathrm{M}$. After $48 \mathrm{~h}, 20 \mu \mathrm{l}$ of MTT was added to each well, after $4 \mathrm{~h}$ the reaction was stopped by addition of a solubilization/stop solution. Absorbance at $590 \mathrm{~nm}$ was measured using multiwell plate reader (Immuno-Mini, NJ-2300, Tokyo, Japan). All experiments were repeated three times. Every experiment was done in triplicate and data are presented as a mean \pm SD value of the 3 individual experiments.

The sensitivity of KP4 to various anticancer drugs under the tranilast treatment was analyzed by MTT assay. KP4 was seeded in 96-well culture plates each $1 \times 10^{4}$ cell/well. After $24 \mathrm{~h}$, the cells were exposed to tranilast (concentration ranging from $0-100 \mu \mathrm{M}$ ) and each drugs for $48 \mathrm{~h}$, at concentrations 0-100 $\mu \mathrm{M}$ for Gem, 0-100 $\mu \mathrm{M}$ for CDDP, 0-1 mM for 5-FU, $0-100 \mu \mathrm{M}$ for CPT-11 and $0-1 \mu \mathrm{M}$ for PTX.

Analysis of BrdU uptake. Uptake of bromodeoxyuridine (BrdU) in KP4 cells was performed according to the protocol of CycLex ${ }^{\circledR}$ Cellular BrdU ELISA kit (Cyclex Co., Ltd., Nagoya, Japan). Briefly, KP4 was seeded in 96-well culture plates $8 \times 10^{3}$ cells/well. After $24 \mathrm{~h}$, the cells were exposed to tranilast at $0,100,200,300,400$ and $500 \mu \mathrm{M}$ concentration for $48 \mathrm{~h}$. BrdU was then added at final concentration of 10 $\mu \mathrm{M}$ and further incubated for $2 \mathrm{~h}$. The cultured cells were treated by fixing/denaturating solution. The cells were treated by anti-BrdU antibody for $1 \mathrm{~h}$, followed by HRP-conjugated anti-mouse IgG. Finally, color development by substrate reagent was measured on the micro plate reader at $450 \mathrm{~nm}$ (Immuno-Mini NJ-2300, Nalge Nunc International Corp., USA).

Reverse transcription-polymerase chain reaction ( $R T-P C R)$ assay. Total RNA was extracted from the cell lines using an Isogen ${ }^{\circledR}$ RNA extraction kit (Nippongene, Toyama, Japan). RT-PCR was carried out using the RNA LA PCR kit (AMV) Version 1.1 (Takara Biochemicals, Shiga, Japan) as previously described (30). The PCR condition following RT reaction were as follows: initial denaturation at $94^{\circ} \mathrm{C}$ for 2 min followed by 30 cycles of $94^{\circ} \mathrm{C}$ for $30 \mathrm{sec}, 60^{\circ} \mathrm{C}$ ribonucleotide reductase subunit 1 (RRM1) or $55^{\circ} \mathrm{C}$ (ß-actin) for $30 \mathrm{sec}$ and $72^{\circ} \mathrm{C}$ for $60 \mathrm{sec}$. PCR for $B$-actin served as an internal standard. The following sense and antisense primers were used: RRM1 primers (5'-GGAGGAATTGGTGTTGCTGT-3' and 5'-GCT GCTCTTCCTTTCCTGTG-3'), 3 -actin primers (5'-TTAAGG AGAAGCTGTGCTACG-3' and 5'-TAGGTGCTTTGATGG AAGTTG-3', respectively). The proposed sizes of PCR products were $235 \mathrm{bp}$ for RRM1 and $208 \mathrm{bp}$ for $\beta$-actin.

Western blot analysis. Pancreas cancer cell lines were seeded in 6 -well culture plates at $2 \times 10^{5}$ cells/well. After $24 \mathrm{~h}$, the cells were exposed to tranilast (concentration range: 0$200 \mu \mathrm{M})$. Forty-eight hours later, cells were lysed in lysis buffer [150 mM NaNl, $50 \mathrm{mM}$ Tris- $\mathrm{HCl}$ (pH 7.6)], 0.5\% Triton X-100 and a protease inhibitor cocktail mix (Roche Diagnostic GmbH, Mannheim, Germany). Twenty micro- 
grams of protein lysate was subjected to Western blot analysis as previously described (30). The primary antibodies used were mouse anti-rebonucleotide reductase monoclonal antibody (MAB3033, 1:500 dilution; Chemicon) and monoclonal anti-ß-actin (Clone AC-15, 1:10000 dilution; Sigma). After incubation with the corresponding secondary antibodies, the signals were developed using an ECL ${ }^{\mathrm{TM}}$ Plus Western blotting detection system (Amersham). For quantitative analysis, band intensities were assessed densitometrically using the LAS 3000 plus system (Fujifilm, Tokyo, Japan).

Cell cycle analysis. KP4 was seeded in 6-well culture plates $2 \times 10^{5}$ cells/well. After $24 \mathrm{~h}$, the cells were exposed to tranilast at $0,100,250$ and $500 \mu \mathrm{M}$ concentration, with or without $1 \mu \mathrm{M}$ Gem for $48 \mathrm{~h}$. For cell-cycle analysis, KP4 cells were harvested using $0.05 \%$ trypsin - $0.02 \%$ EDTA, washed with PBS and fixed in $70 \%$ ice-cold ethanol, stored at $-20^{\circ} \mathrm{C}$. Later, the ethanol was removed, and the cells were stained with propidium iodide (PI) solution $(50 \mu \mathrm{g} / \mathrm{ml}$ in PBS with $100 \mathrm{U} / \mathrm{ml}$ RNase A) (Qiagen $\mathrm{GmbH}$, Hilden) for $30 \mathrm{~min}$ at room temperature in the dark. PI-positive nuclei were analyzed using FACS/Calibur Flow Cytometer (counting 10000 cells per sample) and Cell Quest software Version 2.0 (Becton-Dickinson Co., NJ, USA). Cell population at subG1, G1, S, G2/M phase in each experiment was estimated.

TUNEL assay. KP4 cells were seeded onto Lab-Tec II Chamber Slide ${ }^{\mathrm{TM}}$ System (Nalge Nunc International Corp., USA) $2 \times 10^{4}$ cells/well and cultured for $24 \mathrm{~h}$, The cells were then exposed to tranilast at 0,100 and $250 \mu \mathrm{M}$ with or without $1 \mu \mathrm{M}$ Gem for $48 \mathrm{~h}$. Apoptotic cells were detected using an Apoptosis detection TACS ${ }^{\mathrm{TM}}$ TdT kit (R\&D, Minneapolis, MN, USA). Cells were stained for detecting apoptotic cells according to manufacturer's instructions. Cells developing brown staining in the nuclei were assessed as TUNEL positive cells. The positive cells were counted under the light microscope at x200 magnification in 3 fields. Apoptotic index (AI) was calculated as follows: $\mathrm{AI}=$ (number of apoptotic cells/total number of cells) x $100 \%$ and the mean AI with standard deviation (SD) in 3 fields were determined.

Transient transfection of RRM1 siRNA (ds RNA). For Western blot analysis, $2 \times 10^{5}$ cells of KP4 were seeded onto 6-well plates and incubated overnight. Twenty-one base pairs (bps) of double-strand (ds) RNA for RRM1, which were constructed by iGENE, Co., Ltd. (Tsukuba, Japan), was transiently transfected at 1 and $10 \mathrm{nM}$ concentrations into KP4 cell for $4 \mathrm{~h}$ using a Oligofectamine (Life Technology, Inc., Japan). Randomly constructed dsRNA with a 21-bp length was used as a control (scramble) transfection. At $48 \mathrm{~h}$ after transfection, the protein was extracted from the cell using a lysis buffer [1\% Triton X-100, $50 \mathrm{mM}$ Tris, $150 \mathrm{mM} \mathrm{NaCl}, 0.5 \mathrm{mM}$ phenylmethylsulfonyl fluoride (PMSF)]. The lysate was collected by centrifugation at $15000 \mathrm{rpm}$ for $20 \mathrm{~min}$ and subjected to Western blot analysis.

Effect of RRM1 siRNA on sensitivity to Gem or CDDP was analyzed as follows: $1 \times 10^{4}$ of KP4 cells were seeded onto 6-well plates. dsRNA for RRM1 was transfected in duplicate at a final concentration of 1 or $10 \mathrm{nM}$. Control (scramble) transfection was also done at $10 \mathrm{nM}$. At $24 \mathrm{~h}$ after transfection, the cells were exposed under Gem or CDDP at $5 \mu \mathrm{M}$ concentration for $48 \mathrm{~h}$. The cells were trypsinized and counted under trypan blue staining. Growth inhibition under $5 \mu \mathrm{M}$ Gem or CDDP treatment was estimated in each transfection and the inhibition rate was compared between control dsRNA transfection and RRM1 siRNA.

RRM1 ds RNA design: sense 5'-GAGGAAGAAGAGA AGGAGAGGAACAAG-3' and antisense: UACUCCUUC UUCUCUUCCUCUCCUUGU-5' (iGENE, Co., Ltd.). These experiments were repeated at lease 3 times.

Inhibition of proteasome action by MG132 treatment. KP4 was seeded in 6 -well culture plates at $2 \times 10^{5}$ cells/well. After $24 \mathrm{~h}, 2 \mu \mathrm{M}$ MG132 was added to the culture medium $1 \mathrm{~h}$ prior to tranilast $(0,100,200 \mu \mathrm{M})$ treatment for $48 \mathrm{~h}$. RRM1 protein levels were determined by Western blot analysis using the total cell lysate.

Statistical analysis. Data are shown as the mean \pm standard deviation. The computer software Stat view for Macintosh (Abracus Concepts, Berkely, CA) was used for all statistical analysis. Comparison of means was carried out using the independent t-tests. A p-value of $<0.05$ was considered statistically significant. Bonferoni's correction for multiple testing was performed to determine the p-value with the number of tests.

\section{Results}

The effect of tranilast treatment on cell growth of KP4 cells. To evaluate whether or not tranilast inhibits cell growth of $\mathrm{KP} 4$, the cells were cultured for $48 \mathrm{~h}$ with tranilast at various concentrations (range, 0-400 $\mu \mathrm{M}$ ). As the result, cell proliferation of KP4 was significantly reduced beginning at $200 \mu \mathrm{M}$ tranilast, while the cell growth was not affected $<100 \mu \mathrm{M}$ (Fig. 1A).

Analysis of BrdU uptake was further examined to clarify the effect of tranilast on DNA synthesis in KP4 cell (Fig. 1B). As a result, uptake of BrdU was inhibited by tranilast dosedependently. BrdU uptake was significantly decreased at $>100 \mu \mathrm{M}$ of tranilast, compared with no treatment (Fig. 1B).

The effect of tranilast on sensitivity to various anticancer drugs in KP4 cells. KP4 was exposed to various concentrations of anticancer drugs in the presence or absence of tranilast at $0-100 \mu \mathrm{M}$ concentration. The tranilast drug sensitivity to Gem, CDDP, 5-FU, CPT-11 and PTX was assessed by MTT assay. As shown in Fig. 2A, the responsiveness of $\mathrm{KP} 4$ to Gem was increased with the tranilast treatment in a dose-dependent manner. Sensitivity to CDDP was also increased by tranilast less dose-dependently, while that to 5-FU, CPT-11 or PTX was no longer affected by tranilast (Fig. 2A). As shown in Fig. 2B, cell viability of KP4 was significantly decreased at 50 or $100 \mu \mathrm{M}$ tranilast plus $1 \mu \mathrm{M}$ Gem treatment, compared with the single Gem treatment (upper panel in Fig. 2B). The cell viability was also decreased with statistical significance in tranilast plus $10 \mu \mathrm{M}$ CDDP, in comparison to single CDDP treatment (lower panel in Fig. 2B). 

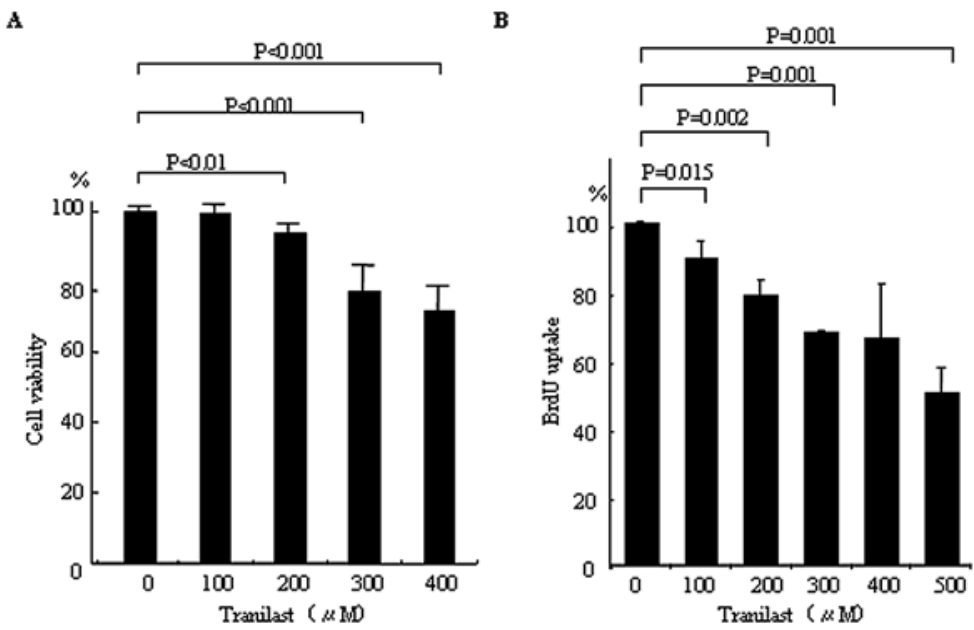

Figure 1. (A) Cell proliferation of KP4 with tranilast at various concentrations. Absorbance at $590 \mathrm{~nm}$ with no tranilast treatment was estimated as $100 \%$ viable in KP4 cell. Cell proliferation was inhibited by tranilast in a dose-dependent manner. (B) Uptake of BrdU in KP4 cells with treatment by tranilast at various concentrations. BrdU uptake was significantly reduced at $>100 \mu \mathrm{M}$, compared with no treatment.

A
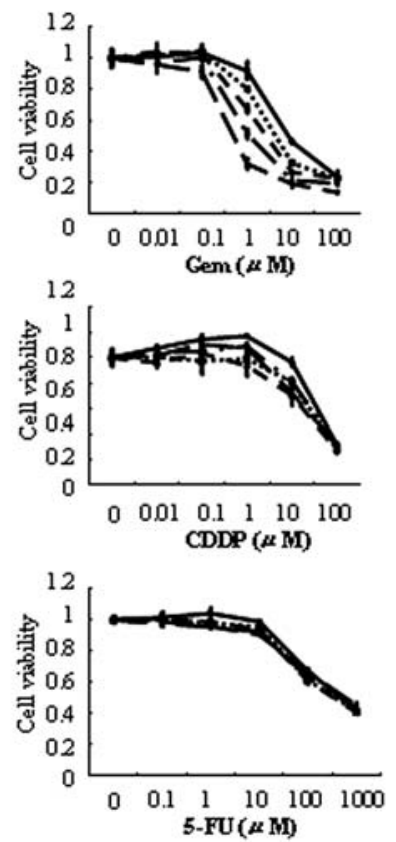

B
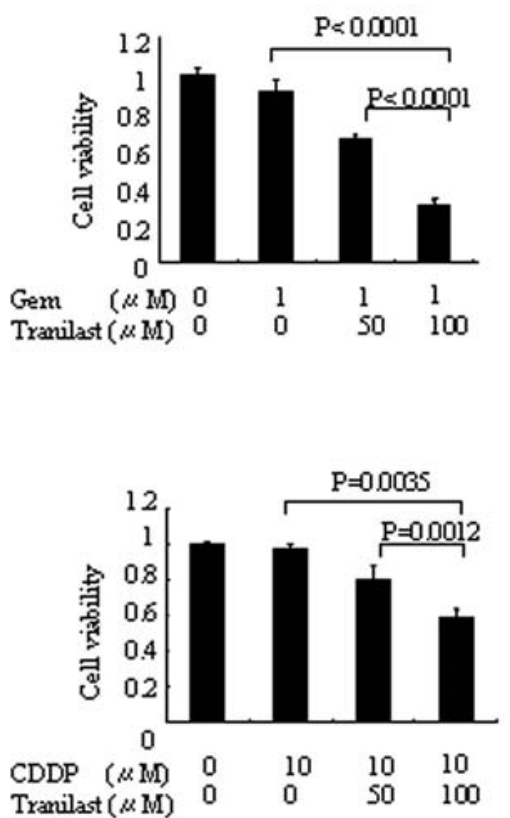

Figure 2. (A) Effects of tranilast on the sensitivity of KP4 to the anticancer drugs gemcitabine (Gem), cisplatin (CDDP), 5-fluorouracil (5-FU), irinotecan (CPT-11) and paclitaxel (PTX) were assessed in MTT assay. (B) In Gem and CDDP treatment, cell viability on the log phase of the graph (A) is represented in the histogram; the drug concentrations of Gem and CDDP were determined at 1 and $10 \mu \mathrm{M}$, respectively. Tranilast concentration was chosen at 0,50 and $100 \mu \mathrm{M}$. Statistical analysis by Boneferoni's correction for multiple testing at $\mathrm{p}<0.0083$ was statistically significant. NS, not significant.

Expression of RRM1 $m R N A$ and protein with tranilast treatment. In order to evaluate whether or not tranilast affects RRM1 mRNA or protein level, RT-PCR and Western blot analysis were performed. The expression of RRM1 mRNA was not influenced by tranilast treatment up to $200 \mu \mathrm{M}$ concentration (Fig. 3A). In contrast, RRM1 protein level was dramatically diminished by tranilast treatment for $48 \mathrm{~h}$ (Fig. 3B). In the quantitative assessment, RRM1 protein level was decreased $56 \%$ at $50 \mu \mathrm{M}, 22 \%$ at $100 \mu \mathrm{M}$ and $20 \%$ at
$200 \mu \mathrm{M}$ of tranilast, compared to $100 \%$ with no treatment (Fig. 3C).

Flow cytometric analysis of cells treated with tranilast and gemcitabine. Flow cytometric analysis was examined to analyze the effect of tranilast or Gem plus tranilast on the cell cycle of KP4 cells. Proportion of cell population at subG1, G1, S, G2/M phase in cell cycle is summarized in Table I. Tranilast treatment at $100 \mu \mathrm{M}$ did not affect the cell 

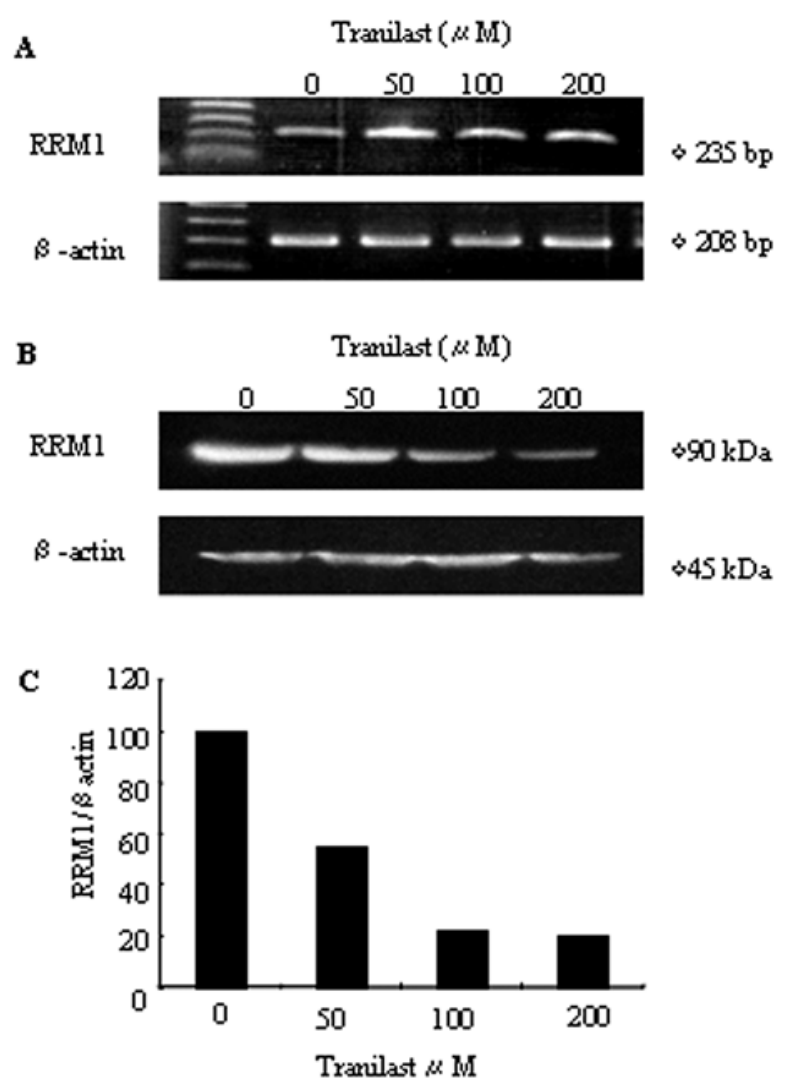

Figure 3. RRM1 expression in KP4 pancreatic cancer cell line with tranilas treatment. (A) RRM1 mRNA expression by RT-PCR analysis. The RRM1 mRNA expression level was not influenced by tranilast at 50, 100 and $200 \mu \mathrm{M}$ concentrations. (B) RRM1 protein and control $\beta$-actin expressions by Western blot analysis. (C) Relative expression of RRM1 protein was analyzed by densitometry. Relative intensity of RRM1 expression was calculated by the normalization of $\beta$-actin expression and shown in the histogram. No treatment of tranilast was considered as $100 \%$.

Table I. Cell cycle analysis of KP4 with the treatment by tranilast and Gem.

\begin{tabular}{lrrrrrrr}
\hline Tranilast $(\mu \mathrm{M})$ & 0 & 100 & 250 & 500 & 0 & 100 & 250 \\
Gem $(\mu \mathrm{M})$ & 0 & 0 & 0 & 0 & 1 & 1 & 1 \\
\hline SubG1 (\%) & 3.0 & 3.7 & 3.4 & 4.2 & 15.9 & 31.3 & 39.2 \\
G1 $(\%)$ & 74.0 & 73.0 & 79.3 & 89.5 & 70.2 & 55.1 & 47.8 \\
S $(\%)$ & 5.0 & 5.1 & 4.8 & 3.0 & 2.5 & 2.5 & 2.4 \\
G2/M (\%) & 18.0 & 18.2 & 12.5 & 3.3 & 11.4 & 11.1 & 10.6 \\
\hline
\end{tabular}

population at G1 phase (73.0\%), compared with no treatment (74.0\%). However, higher dose of tranilast at 250 and $500 \mu \mathrm{M}$ increased cell proportion at G1 phase up to 79.3 and $89.5 \%$, respectively.

On the other hand, with Gem plus tranilast, $1 \mu \mathrm{M}$ Gem along with 100 or $250 \mu \mathrm{M}$ of tranilast increased the percentage of sub-G1 phase up to 31.3 and $39.2 \%$ in KP4 cells, compared with $15.9 \%$ in Gem treatment alone.

TUNEL assay. Population of apoptotic cells exposed with tranilast plus Gem were estimated by TUNEL assay as shown
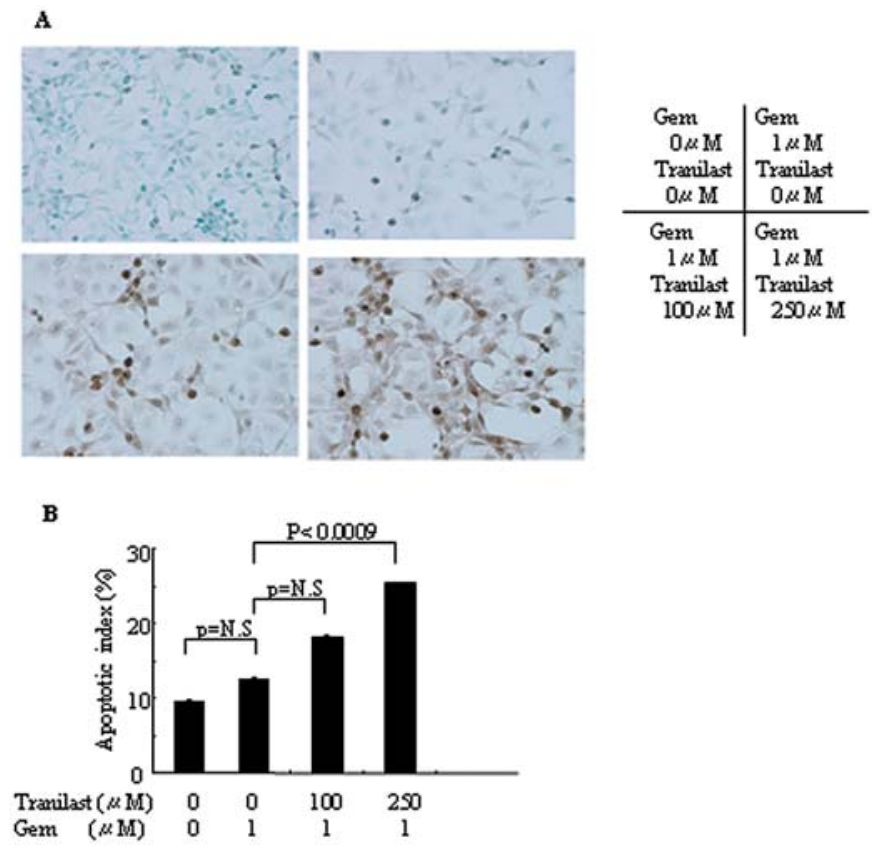

Figure 4. (A) KP4 cells treated by 0,100 and $250 \mu \mathrm{M}$ of tranilast with or without $1 \mu \mathrm{M}$ Gem are shown. Apoptotic cells with nucleus stained brown were increased at treatment with 100 or $250 \mu \mathrm{M}$ of tranilast and $1 \mu \mathrm{M}$ of Gem. (B) Histogram of mean AI in the combination treatment of tranilast and $\mathrm{dFdC}$. Mean AI is shown above each treatment. There was statistically significant difference in apoptotic index between the treatment of $1 \mu \mathrm{M} \mathrm{Gem}$ alone and treatment of $1 \mu \mathrm{M}$ Gem plus tranilast at $250 \mu \mathrm{M}$ concentration.

in Fig. 4A. Number of brown color stained nuclei was counted and the apoptotic index was estimated. Mean apoptotic index (AI) was increased up to $18.3 \%$ in $1 \mu \mathrm{M}$ Gem plus $100 \mu \mathrm{M}$ tranilast and $25.4 \%$ in $1 \mu \mathrm{M}$ Gem plus $250 \mu \mathrm{M}$ tranilast, compared with $9 \%$ in no treatment and $12 \%$ in $1 \mu \mathrm{M} \mathrm{Gem}$ (Fig. 4B). Mean AI was significantly higher in the combination treatment of $1 \mu \mathrm{M}$ Gem plus $250 \mu \mathrm{M}$ tranilast, compared with $1 \mu \mathrm{M}$ Gem treatment.

Down-regulation of RRMI by siRNA transfection. In order to analyze the direct effect of RRM1 on Gem sensitivity, siRNA (dsRNA) against RRM1 gene was transiently transfected into KP4 cells and cell viability under Gem treatment in RRM1 siRNA transfectant was compared with that in the control siRNA transfectant. At $48 \mathrm{~h}$ after the transfection, RRM1 protein expression was repressed by RRM1 siRNA transfection, compared with control siRNA (Fig. 5A). Using these transfectants, viable cells with or without Gem treatment was counted. In the transfection by $10 \mathrm{nM}$ control siRNA, viable cells were decreased to $52.9 \%$ at $5 \mu \mathrm{M}$ of Gem. Cell viability with Gem treatment was further reduced 36.7 and $25.5 \%$ by RRM1 siRNA transfection at 1 and $10 \mathrm{nM}$ concentration, respectively (Fig. 5B). There was statistically significant difference in cell viability between $10 \mathrm{nM}$ of control siRNA and $10 \mathrm{nM}$ of RRM1 siRNA transfectant with the treatment of Gem $(p=0.0014)$. Also in the CDDP treatment, RRM1 siRNA transfection decreased more strongly the viable cells treated with $5 \mu \mathrm{M}$ CDDP, compared with the control siRNA transfection. However, there was no significant 

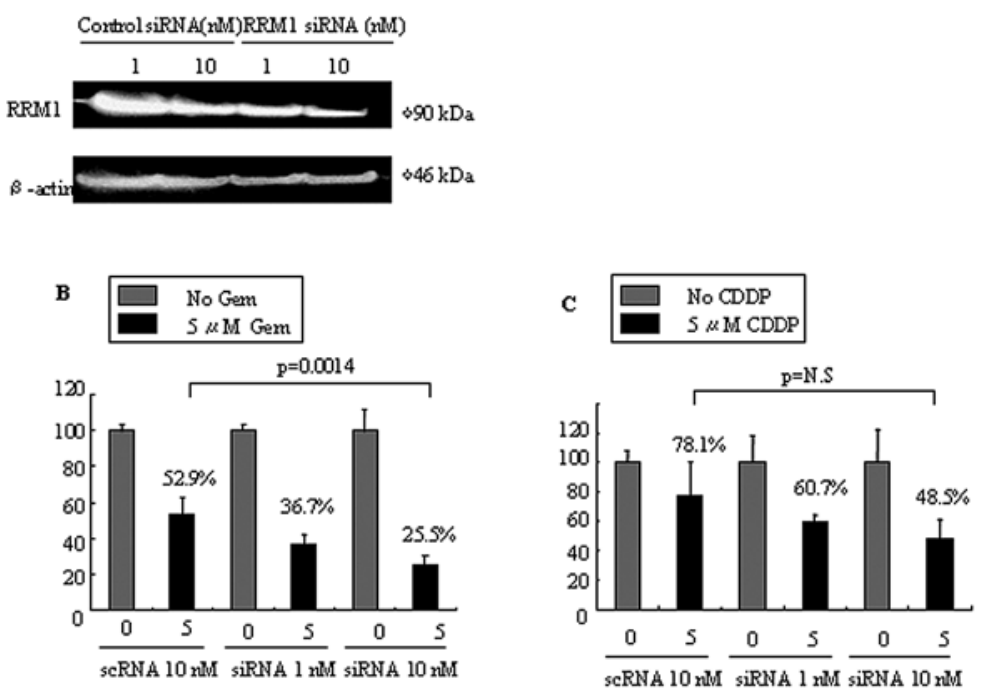

Figure 5. (A) Western blot analysis of RRM1 expression in KP4 cells transfected by siRNA against RRM1 or scRNA (control) at each 1 and $10 \mathrm{nM}$ concentration. (B) Effect of RRM1 siRNA transfection on cell growth with or without Gem treatment. The percentage of cell number under $5 \mu \mathrm{M}$ Gem treatment was estimated as the cell number with no treatment was considered 100\% in each siRNA transfection. The survival percentages are given above the black bar. Cell viability of $10 \mathrm{nM}$ RRM1 siRNA transfectant under Gem treatment was significantly lower than that of $10 \mathrm{nM}$ scRNA transfectant. (C) Effect of RRM1 siRNA transfection on cell growth with or without CDDP treatment. Cell viability of $10 \mathrm{nM}$ RRM1 siRNA transfectant with CDDP treatment was lower than that of $10 \mathrm{nM}$ scRNA transfectant, although not statistically significant.

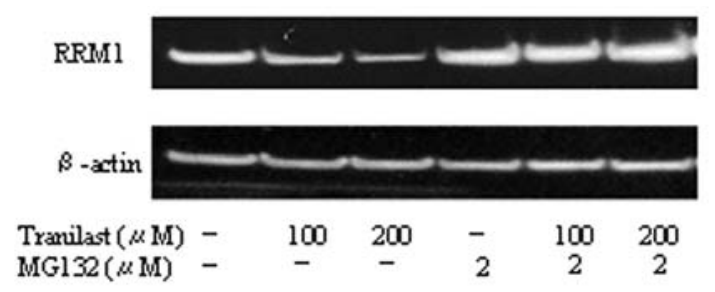

Figure 6. Effect of proteasome inhibitor MG132 on RRM1 expression with tranilast treatment in KP4 cells. Under the presence of MG132 proteasome inhibitor at $2 \mu \mathrm{M}$, the tranilast-induced reduction of RRM1 expression was disturbed.

difference between $10 \mathrm{nM}$ of control siRNA and $10 \mathrm{nM}$ of RRM1 siRNA transfectection (Fig. 5C).

Effect of proteasome inhibitor, MG132 on RRM1 expression in KP4 cells with tranilast. To examine whether or not proteasome-mediated degradation acts on the RRM1 suppression by tranilast, KP4 cells were exposed to tranilast in the presence or absence with the specific proteasome inhibitor MG132. As shown in Fig. 6, RRM1 was decreased by tranilast at 100 and $200 \mu \mathrm{M}$ concentration. However, the reduced RRM1 expression by tranilast was completely abolished with MG132 treatment.

The effect of tranilast treatment on $d F d C$ sensitivity in other pancreas cell lines. We investigated whether or not the synergistic effect of tranilast toward Gem sensitivity is found in the pancreatic cancer cell lines PK-8, PK-9, PK-1 and PK-59. Expression of RRM1 protein in these cells under tranilast treatment at concentration of 50, 100 and $200 \mu \mathrm{M}$ was analyzed in Western blot and the expression level was quantitatively assessed (Fig. 7). As a result, RRM1 expression declined with tranilast treatment (ranging from 62.3 to $5.1 \%$ at $200 \mu \mathrm{M}$ tranilast) (Fig. 7). The effect of tranilast on Gem sensitivity was then analyzed in MTT assay and the $\mathrm{IC}_{50}$ for Gem was calculated in all the cell lines including KP4. As summarized in Table II, 50 or $100 \mu \mathrm{M}$ tranilast plus Gem treatment significantly decreased $\mathrm{IC}_{50}$ for Gem in KP4, PK-8, PK-9, PK-1 and PK-59 cells, compared with single Gem treatment.

\section{Discussion}

Ribonucleotide reductase (RNR) catalyzes the conversion of ribonucleotides into the correspondent 2'-deoxyribonucleotides in the rate-limiting step for the biosynthesis of DNA $(9,10,31)$. This enzyme thus has long been regarded as an important target for cancer therapies. The enzymatic activity of RNR was shown to be dependent on the formation of a complex between two different dimers composed of larger subunit (RRM1) and smaller subunit (RRM2) (31). Various inhibitors targeting on RRM1 or RRM2 have been developed and the in vitro and in vivo effects examined (31). Among the RNR inhibitors, Gem inhibits RRM1 activity by which Gem metabolite, $\mathrm{dFdCDP}$ is misincorporated at the active site, leading to no more DNA replication (31). Recently, clinical use of Gem has been approved by the FDA for the treatment of patients with non-small cell lung cancer and adenocarcinoma of the pancreas $(7,8)$. Current reports demonstrated that overexpression of RRM1 is linked to Gem resistance in human cancers (11-16). Using DNA array system, Davidson et al isolated RRM1 as the most critical gene determining Gem resistance in non-small cell lung cancer cell line (11). Thereafter several studies reported a significant 

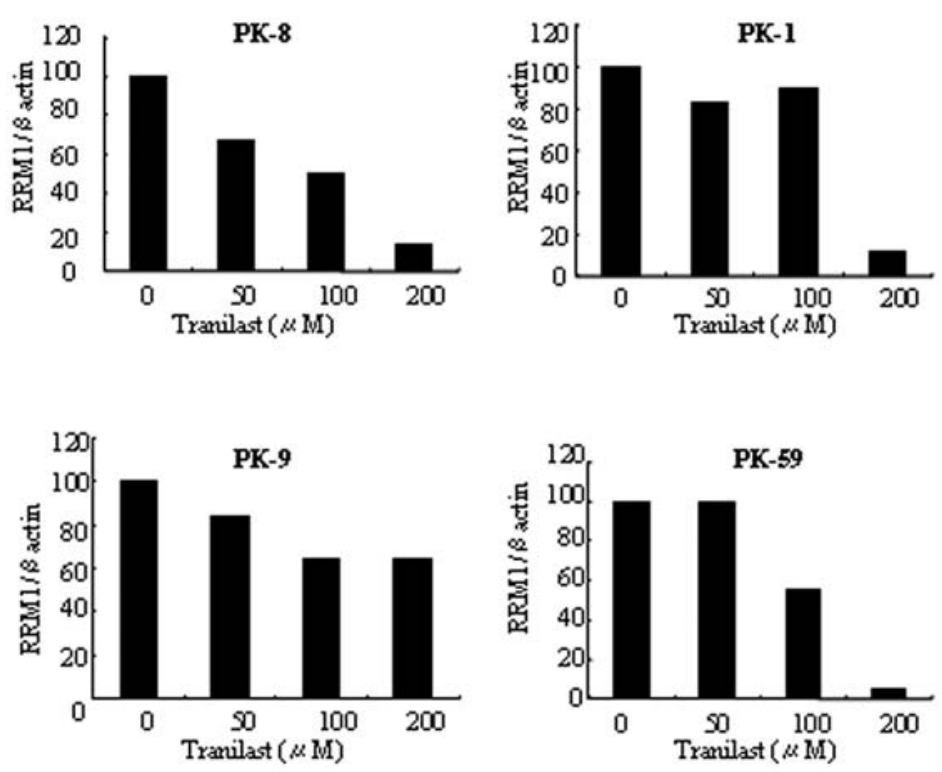

Figure 7. (A) Western blot analysis of RRM1 expression using the pancreatic cancer cells PK-8, PK-9, PK-1 and PK-59 with tranilast treatment at 50, 100 and $200 \mu \mathrm{M}$. Intensity of RRM1 signal in each cell was analyzed in LAS3000 and normalized by that of B-actin. The relative intensity (\%) was calculated as no treatment of tranilast and considered $100 \%$.

Table II. $\mathrm{IC}_{50}$ values of Gem in pancreatic cancer cells with tranilast treatment at various concentrations.

\begin{tabular}{lrrrr}
\hline $\begin{array}{l}\text { Cell } \\
\text { lines }\end{array}$ & $\begin{array}{c}\text { Tranilast } \\
(\mu \mathrm{M})\end{array}$ & $\begin{array}{c}\mathrm{IC}_{50} \\
(\mu \mathrm{M})\end{array}$ & $\mathrm{SD}$ & P-value \\
\hline KP4 & 0 & 9.29 & 0.12 & \\
& 50 & 4.83 & 0.29 & $<0.0001$ \\
& 100 & 0.73 & 0.06 & $<0.0001$ \\
PK-8 & 0 & 78.8 & 75.0 & \\
& 50 & 45.1 & 15.5 & 0.039 \\
& 100 & 8.6 & 1.6 & 0.017 \\
PK-9 & 0 & 96.1 & 26.5 & \\
& 50 & 76.7 & 8.85 & 0.0048 \\
& 100 & 72.2 & 56.9 & 0.011 \\
PK-1 & 0 & 108.1 & 6.4 & \\
& 50 & 75.1 & 17.7 & 0.038 \\
& 100 & 62.2 & 8.7 & 0.0018 \\
PK-59 & 0 & 84.3 & 1.9 & \\
& 50 & 41.4 & 7.5 & 0.0007 \\
& 100 & 11.1 & 3.5 & $<0.0001$ \\
\hline
\end{tabular}

$\mathrm{p}<0.05$; statistically significant.

correlation between the RRM1 expression and Gem resistance in non-small cell lung carcinoma cell lines and tissues (12-14). In pancreatic cancer, literature demonstrates that RRM1 is a key molecule in Gem resistance through both in vitro and clinical models $(15,16)$. These reports indicate that attenuation of RRM1 expression in both pancreatic and non-small cell lung cancer might contribute to overcome the resistance to Gem.

Tranilast has been found to inhibit the release of transforming growth factor (TGF)- $\beta$, interleukin (IL)-1ß, prostaglandin (PG) E2 and IL-2 from human monocytes and macrophages (18). The result led to the clinical use of this compound for allergic diseases. Several studies have demonstrated the growth inhibition effect by tranilast in several types of cancer cells (26-29). Platten et al reported growth inhibition of malignant glioma cells by tranilast treatment (27). Shime et al showed that tranilast treatment induced growth arrest of leiomyoma cells at G0/G1 phase with p21 and p53 expression (29).

In the present study, tranilast treatment significantly inhibited cell growth of KP4 cells at 200-400 $\mu \mathrm{M}$ (Fig. 1A). Furthermore, uptake of BrdU was inhibited by tranilast treatment at more than $100 \mu \mathrm{M}$ concentration. FACS analysis revealed the increased G1 fraction by the high dose treatment of tranilast at 250 or $500 \mu \mathrm{M}$ (Table I). These results indicated that tranilast treatment inhibited cell growth of KP4 and rendered the cells arrested at $\mathrm{G} 1$ phase, at more than $250 \mu \mathrm{M}$ concentration. Previous reports demonstrated similar findings that $300 \mu \mathrm{M}$ of tranilast induced growth arrest in both glioma and leiomyoma cells $(27,29)$.

On the contrary, combination experiment using anticancer drugs revealed that tranilast remarkably increased Gem sensitivity of KP4 cells at concentrations ranging from 25 to $100 \mu \mathrm{M}$ (Fig. 2).

As tranilast at $100 \mu \mathrm{M}$ did not affect cell growth of KP4 (Fig. 1A), it was indicated that tranilast synergistically enhanced Gem efficacy to KP4 cells. This compound also increased the efficacy of CDDP, although the synergistic effect was less than that to Gem (Fig. 2). However, tranilast no longer influenced the sensitivity to 5FU, CPT-11 or PTX in KP4 cells (Fig. 2A). This notable difference provided us a 
hypothesis that tranilast could alter the expression of some important molecule determining Gem or CDDP sensitivity. As expected, tranilast dramatically reduced protein expression of a target molecule of Gem, RRM1 dosedependently at 50-200 $\mu \mathrm{M}$ (Fig. 3B, C). This result indicated that the dose-dependent reduction of RRM1 protein resulted in the decreased uptake of BrdU (Fig. 1B) and G1 phase arrest at 250, $500 \mu \mathrm{M}$ tranilast in FACS analysis (Table I). On the other hand, apoptotic effect by Gem was strongly accelerated in KP4 under the combined treatment at 100 and $250 \mu \mathrm{M}$ tranilast (Table I, Fig. 4). It is thus speculated that tranilast decreases RRM1 expression and thereafter the Gem metabolite, dFdCDP, might easier inactivate the smaller amount of RRM1, leading to the strong induction of cell apoptosis in KP4.

To further confirm the effect of RRM1 expression in drug sensitivity to Gem or CDDP, transfection experiment using siRNA was carried out. The result demonstrated that siRNA against RRM1 significantly reduced the number of living KP4 cells exposed at $5 \mu \mathrm{M}$ of Gem, compared with the control siRNA transfection, indicating that the sensitizing effect of tranilast on Gem mainly depends on the reduced RRM1 expression (Fig. 5B). Sensitivity to CDDP was also increased in RRM1 siRNA transfectant (Fig. 5C), although there was no statistical significance. CDDP is believed to kill cancer cells by binding to DNA and interfering with its repair mechanism. Harrington et al previously reported that CDDP irreversibly inhibits RNR activity via binding to RRM1 (32). Bepler et al showed that transfection of RRM1 siRNA increased sensitivity not only to Gem with 100-fold range, but also to CDDP with 2-fold range in non-small cell lung cancer cells (14). These reports support our result that RRM1 suppression by tranilast also contributes to the elevated CDDP sensitivity in KP4 cells.

To investigate the mechanism of RRM1 suppression, RRM1 expression was analyzed with tranilast along with MG132. As a result, RRM1 suppression by tranilast was abolished by MG132 treatment (Fig. 6). This result suggested that RRM1 degradation proceeds through the activated proteasome pathway. Proteasome inhibitor MG132 might cancel the tranilast effect on the enhancement of Gem toxicity through the inhibited RRM1 degradation. At present, the more precise mechanisms such as poly-ubiquitination of RRM1 protein under tranilast treatment, leading to RRM1 degradation by proteasome, remain to be elucidated.

To assess the feasibility of combined tranilast plus Gem therapy, the effect of tranilast on Gem sensitivity was investigated using other pancreatic cancer cell lines. In Western blot analysis, RRM1 expression was decreased in PK-8, PK-9, PK-1 and PK-59 by tranilast treatment (Fig. 7). In MTT assay, tranilast significantly decreased the $\mathrm{IC}_{50}$ for $\mathrm{Gem}$ in the cell lines as shown in KP4 (Table II). These results indicated that tranilast decreased RRM1 expression in all the pancreatic cancer cell lines tested and the reduced RRM1 expression is necessary to enhance the responsiveness to Gem.

Previous report showed that the concentration of tranilast in human plasma was estimated at 30-300 $\mu \mathrm{M}$ in case of daily oral intake of $600 \mathrm{mg}$ tranilast for the treatment of allergic patients, suggesting the reasonable setting of tranilast concentration in the present in vitro study (22). Tranilast is usually taken orally and found to have few side effects except eosinophilic cystitis (33). In conclusion, tranilast induces protein degradation of RRM1 in pancreatic cancer and thereafter Gem might easier inactivate the smaller amount of RRM1, resulting in strong inhibition of cancer growth. Therefore, Gem plus tranilast would be a promising combination therapy against this malignancy. A clinical trial comparing the single Gem treatment with Gem plus tranilast should be performed in pancreatic cancer patients.

\section{References}

1. Warshaw AL and Fernandez-del Castillo C: Pancreatic carcinoma. N Engl J Med 326: 455-465, 1992.

2. Gruzburn WH and Salmon B: Novel clinical strategies for the treatment of pancreatic carcinoma. Trends Mol Med 7: 30-37, 2001.

3. Vento P, Mustonen H, Joensuu T, Karkkainen P, Kivilaakso E and Kiviluoto $\mathrm{T}$ : Impact of preoperative chemoradiotherapy on survival in patients with respectable pancreatic cancer. World J Gastroenterol 13: 2945-2951, 2007.

4. Smeenk HG, Tran TCK, Erdmann J, van Eijck CH and Jeelel J: Survival after surgical management of pancreatic adenocarcinoma: does curative and radical surgery truly exist? Langenbecks Arch Surg 390: 94-103, 2005.

5. Yeo C, Abrams R, Grochow LB, et al: Pancreaticoduodenectomy for pancreatic adenocarcinoma: postoperative adjuvant chemoradiation improves survival. A prospective, single-institution experience. Ann Surg 225: 621-633, 1997.

6. Wagner M, Redaelli C, Lietz M, Seiler CA, Friess H and Buchler MW: Curative resection is the single most important factor determining outcome in patients with pancreatic adenocarcinoma. Br J Surg 91: 586-594, 2004.

7. Burris HA III, Moore MJ, Andersen J, et al: Improvements in survival and clinical benefit with gemcitabine as first-line therapy for patients with advanced pancreas cancer: a randomized trial. J Clin Oncol 15: 2403-2413, 1997.

8. O'Reilly EM and Abou-Alfa GK: Cytotoxic therapy for advanced pancreatic adenocarcinoma. Semin Oncol 34: 347-353, 2007.

9. Pereira S, Fernandes A and Ramos MJ: Computational studies on class I ribonucleotide reductase: understanding the mechanisms of action and inhibition of a cornerstone enzyme for the treatment of cancer. Eur Biophys J 35: 125-135, 2006.

10. Pereira S, Fernandes PA and Ramos MJ: Mechanism for ribonucleotide reductase inactivation by the anticancer drug gemcitabine. J Comput Chem 25: 1286-1294, 2004.

11. Davidson JD, Ma L, Flagella M, Geeganage S, Gelbert LM and Slapak CA: An increase in the expression of ribonucleotide reductase large subunit 1 is associated with gemcitabine resistance in non-small cell lung cancer cell lines. Cancer Res 64: 3761-3766, 2004.

12. Rosell R, Danenberg KD, Alberola V, et al: Ribonucleotide reductase messenger RNA expression and survival in gemcitabine/cisplation-treated advancer non-small cell lung cancer patients. Clin Cancer Res 10: 1318-1325, 2004.

13. Bergman AM, Eijk PP, Ruiz van Haperen VW, Smid K, Veerman G, Hubeek I, van den Ijssel P, Ylstra B and Peters GJ: In vivo induction of resistance to gemcitabine results in increased expression of ribonucleotide reductase subunit M1 as the major determinant. Cancer Res 65: 9510-9516, 2005.

14. Bepler G, Kusmartseva I, Sharma S, Gautam A, Cantor A, Sharma A and Simon G: RRM1 modulated in vitro and in vivo efficacy of gemcitabine and platinum in non-small cell lung cancer. J Clin Oncol 24: 4731-4737, 2006.

15. Nakano Y, Tanno S, Nishikawa T, et al: Gemcitabine chemoresistance and molecular markers associated with gemcitabine transport and metabolism in human pancreatic cancer cells. Br J Cancer 96: 457-463, 2007.

16. Nakahira S, Nakamori S, Tsujie M, et al: Involvement of ribonucleotide reductase M1 subunit overexpression in gemcitabine resistance of human pancreatic cancer. Int J Cancer 120: 1355-1363, 2007.

17. Azuma H, Banno Y and Yoshimura T: Pharmachological properties of $\mathrm{N}-\left(3^{\prime}, 4^{\prime}\right.$-dimethoxycinnamoyl) anthranilic acid (N-5'), a new anti-atopic agent. Br J Pharmacol 58: 483-488, 1976. 
18. Yanagi T, Watanabe M, Fukuda S and Tsuji Y: Suppressive effects of tranilast on human mononuclear cells. Jpn J Inflam 7: 169-173, 1987

19. Koda A, Nagai H, Watababe S, Yanagihara Y and Sakamoto K: Inhibition of hypersensitivity reactions by a new drug, $\mathrm{N}-\left(3^{\prime}, 4^{\prime}-\right.$ dimethoxycinnamoyl) anthranilic acid $\left(\mathrm{N}-5^{\prime}\right)$. J Allergy Clin Immunol 57: 396-407, 1976.

20. Yamada H, Tajima S, Nishikawa T, Murad S and Pinnell SR: Tranilast, a selective inhibitor of collagen synthesis in human skin fibroblasts. J Biochem 116: 892-897, 1994.

21. Isaji M, Miyata H, Ajisawa I and Takehara Y: Tranilast inhibits proliferation, chemotaxis and tube formation of human microvascular endothelial cells in vitro and angionesis in vivo. Br J Phamacol 122: 1061-1066, 1997.

22. Kusama H, Kikuchi S, Tazawa S, et al: Tranilast inhibits the proliferation of human coronary smooth muscle cell through the activation of p21waf1. Atherosclerosis 143: 307-313, 1999.

23. Isaji M, Aruga N, Naito $\mathrm{J}$ and Miyata $\mathrm{H}$ : Inhibition by tranilast of collagen accumulation in hypersensitive granulomatous inflammation in vivo and of morphological changes and functions of fibroblasts in vitro. Life Sci 55: 287-292, 1994

24. Fukuyama J, Ichikawa K, Miyazawa K, Hamano S, Shibata N and Ujiie A: Tranilast suppresses intimal hyperplasia in the balloon injury madel and cuff treatment model in rabbits. Jpn J Pharmacol 70: 321-327, 1996.

25. Cooper K, Young J, Wadsworth S, Cui H, DiZerega GS and Rodgers KE: Reduction of post-surgical adhesion formation with tranilast. J Surg Res 141: 153-161, 2007.

26. Yatsunami J, Aoki S, Fukuno Y, Kikuchi Y, Kawashima M and Hayashi SI: Antiangiogenic and antitumor effects of tranilast on mouse lung carcinoma cells. Int J Oncol 17: 1151-1156, 2000.
27. Platten M, Wild-Bode C, Wick W, Leitlein J, Dichgans J and Weller M: N-(3,4-dimethoxycinnamoyl)-anthranilic acid (tranilast) inhibits transforming growth factor- $\beta$ release and reduces migration and invasiveness of human malignant gliomacells. Int J Cancer 93: 53-61, 2001.

28. Hiroi M, Onda M, Uchida E and Aimoto T: Anti-tumor effect of $\mathrm{N}$-(3,4-dimethoxycinnamoyl)-anthranilic acid (tranilast) on experimental pancreatic cancer. J Nippon Med Sch 69: 224-234, 2002.

29. Shime H, Kariya M, Orii A, et al: Tranilast inhibits the proliferation of uterine leiomyoma cells in vitro through G1 arrest associated with the induction of $\mathrm{p} 21^{\text {wafl }}$ and $\mathrm{p} 53$. J Clin Endocrinol Metab 87: 5610-5617, 2002.

30. Kitajima $\mathrm{Y}$, Ide $\mathrm{T}$, Ohtsuka $\mathrm{T}$ and Miyazaki K: Induction of hepatocyte growth factor activator gene expression under hypoxia activates the hepatocyte growth factor/c-Met system via hypoxia inducible factor-1 in pancreatic cancer. Cancer Sci 99: 1341-1347, 2008.

31. Cerqueira N, Pereira S, Fernandes PA and Ramos MJ: Overview of ribonucleotide reductase inhibitors: an appealing target in anti-tumor therapy. Curr Med Chem 12: 1283-1294, 2005.

32. Harrington JA and Spector T: Human ribonucleotide reductase. Activation and inhibition by analogs of ATP. Biochem Pharmacol 42: 759-763, 1991.

33. Nakada T, Ishikawa S, Sakamata M, et al: N-(3',4'-dimethoxycinnamoyl) anthranillic acid, an antiallergic compound, induced eosinophilic cystitis. Urol Int 41: 457-464, 1986. 